\title{
Collaborative Governance Challenges of the COVID-19 Pandemics: Czech Republic and Slovakia
}

\author{
Daniel Klimovský \\ Comenius University Bratislava, Slovakia \\ University of Pardubice, Czech Republic \\ daniel.klimovsky@uniba.sk \\ https://orcid.org/0000-0002-0312-2842 \\ Ivan Malý \\ Masaryk University Brno, Czech Republic \\ ivan.maly@econ.muni.cz \\ https://orcid.org/0000-0001-6551-895X \\ Juraj Nemec \\ Masaryk University Brno, Czech Republic \\ juraj.nemec@umb.sk \\ https://orcid.org/0000-0002-5881-7422
}

Received: 28.1.2021

Accepted: 20. 4. 2021

\section{ABSTRACT}

The goal of this article is to evaluate what the Czech and Slovak governments have done to protect their countries and try to assess why they have achieved different results for the first and second waves of the Covid-19 pandemic. The basis for such evaluation is the concept of collaborative governance, while qualitative research methods are used to achieve this goal. Based on comprehensive case studies and following analysis, the article suggests that in countries with limited quality of collaborative governance and no experience in similar pandemics, short-term "ultramobilisation" and positive results are indeed possible, but failures are non-avoidable in the long run. During the second wave of the pandemic, the weaknesses in governance resulted in massive governance failures. As a result, the governments' responses delivered very limited results in terms of prevalence of Covid-19.

Keywords: collaborative governance, Covid-19, Czech Republic (Czechia), Slovakia JEL: H12 


\section{Introduction}

By mid-January 2021, several hundred thousand articles have been published in relation to COVID-19. These articles naturally have different focus and many try to explain the varying success rates of anti-pandemic policies implemented by national governments (Bouckaert et al., 2020; Capano et al., 2020 ; Joyce et al. 2020). Several studies, e.g. Ansell et al., 2020, propose that one of the core factors determining the state success or failure in fighting the spread of the pandemic might be high quality collaborative governance with competent politicians, reliable and professional bureaucracy and cooperation and high trust from society.

Although there аге numerous aspects of the COVID-19 crisis which make it a thorny policy problem, a key aspect of this crisis is its novel character (Capano et al., 2020). Therefore, it is important to look closely at this aspect and to find out what the successful governments have done to protect their countries and why they achieved positive (or negative) results, with special regard to collaborative governance and its elements.

According to Capano et al. (2020), the national governments can be classified in relation to the first wave of COVID-19 pandemic as follows:

1) governments which were prepared for pandemics and had recent similar past experiences: information and capacity pushed them towards relatively early, slow but steady and strong responses;

2) governments which were prepared for pandemics (especially because of their high-quality health systems), but with no or only out-dated relevant past experiences with such pandemics: they tended to feature later, slower and weaker responses than their more experienced counterparts;

3) governments that were unprepared in the sense of having scant-dedicated resources directed towards emergencies but who had recent past experience dealing with similar kinds of diseases and crises: they reacted early and quickly and in a very strong fashion to quell a newly emerging threat before it could get established;

4) governments that were both unprepared and had no recent relevant past experience: these governments were complacent initially and then shocked as the true nature of the pandemic and their lack of preparedness were revealed; they were late and slow in responding and then had a strong (panic) response.

This classification is indirectly supported by authors suggesting that path dependency, in the sense of previous experience with similar crises (like SARS), helped in dealing with the COVID-19 pandemic (Liu and Saltman, 2020).

If such classification is valid, the question is generated - why the Czech Republic (Czechia) and Slovakia (as well as some other Central and Eastern Europe countries) managed to limit the spread of the COVID-19 pandemic so well in spring and why they failed in the later phases of the pandemic? Both 
countries were unprepared and inexperienced. Moreover, according to existing international indicators, these countries do not have robust governance and administrative capacities necessary to be able to respond to turbulent problems (e.g., Thijs et al., 2017).

Was the success in spring just luck (like in sports, when outsiders might sometimes win), or a combination of several specific factors (not yet proposed in a comprehensive way by any author) or anything else? And was the failure in autumn just confirmation of the fact that with their background countries like Czechia and Slovakia may achieve short-term successes, but cannot deliver sustainable high-quality results?

The goal of this article is to evaluate pandemic developments in Czechia and Slovakia in terms of the activities of their governments. To discover reasons for significantly different results in the initial phase and later phases of the pandemic and if elements of collaborative governance are being observed. Qualitative research methods are used to achieve this goal. The main research question to be posed is "Why did the Czech and Slovak governments achieve different results for the first and second phases of the pandemic?".

The structure of this article is as follows - after the literature review the authors deliver two case studies, highlighting what the Czech and Slovak governments have done to protect their countries and which health results have been achieved. On the basis of these case studies, selected critical elements of collaborative governance possibly determining results in the first and second phase of COVID-19 pandemics are analysed. The final part of the text draws on the findings and formulates conclusions.

\section{Collaborative governance and the COVID-19 pandemic: Literature review}

Ansell et al. (2020) interlinked the COVID-19 crisis with turbulent problems that are characterised by surprising, inconsistent, unpredictable, and uncertain events. In the cases of great uncertainty and unexpected challenges, only robust systems of governance may remain operational according to many authors (e.g., Howlett et al., 2018).

Taking into account a requirement to use the strengths of robust systems of governance against the pandemic crisis, Ansell et al. (2020) looked deeper at robust governance strategies (including scalability, prototyping, modularisation, bounded autonomy, bricolage, and strategic polyvalence) and proposed several implications for public administration, including usefulness of collaborative governance. Such suggestions can be supported, inter alia, by Ramus et al. (2017) who pointed out that multi-actor collaboration is a crucial precondition for robust governance strategies or by Bryson et al. (2006) who considered a cross-sectoral collaboration a remedy for complex public problems. From this point of view, the most affected stakeholders in particular cannot be excluded from collaboration (Parker et al., 2020). Since the present pan- 
demic crisis is of a global nature and is somewhat difficult and problematic to identify the most affected stakeholders, such circumstances can, according to Ansell and Torfing (2015) lead to tensions inherent in collaboration across scales or at multiple scales. From this perspective, a traditional understanding of collaboration rooted especially in mutual respect, trust and shared capacities needs to be upgraded to a dynamically scaling collaboration that can adapt to turbulent problems and volatile demands.

As for collaborative governance, its fundamental features are described by the following definition: "A governing arrangement where one or more public agencies directly engage non-state stakeholders in a collective decision-making process that is formal, consensus-oriented, and deliberative and that aims to make or implement public policy or manage public programs or assets" (Ansell and Gash, 2008, p. 544).

The starting conditions are decisive for the quality of collaboration and can be either encouraging or discouraging for various stakeholders. In addition, a series of other factors influences the quality of collaboration, namely faceto-face dialogue, trust building, development of commitment, and shared understanding (Ansell and Gash, 2008). However, according to Emerson et al. (2012), besides the mentioned conditions, it is important to keep in mind the essential drivers (namely leadership, consequential incentives, interdependence, and uncertainty) without which the impetus for collaboration cannot successfully unfold. The pandemic directly "provides" three drivers of collaborative governance, namely consequential incentives (because it was a kind of external threat), uncertainty (due to the turbulent and novel nature of the problems which followed the beginning of the pandemic), and interdependence (the pandemic was too complex, and no individual government could solve it on its own). The fourth driver, i.e., leadership, is a crucial element of coping with any kind of large-scale crisis. Due to the rapid spread of COVID-19, the countries had to employ various measures, including significant shifts of system settings such as crisis management. While crisis management in Czechia, as well as Slovakia, traditionally requires hierarchical leadership and top-down decision-making, the concept of collaborative governance is based rather on facilitative leadership and inclusive consensus-oriented decisionmaking. This difference offers an interesting research impetus. Especially if one takes into account different results of responses of these countries during the first wave and the following wave(s) of the COVID-19 pandemic.

Within this context, Huang (2020) demonstrated that a collaborative governance model played an important role in Taiwan. First of all, it contained trustful cooperation between the central and local governments, but also a clear coordination with other actors (e.g., NGOs), and mobilisation of some corporate resources. At the end of the day, a combination of well-implemented measures to block, track, and isolate possible sources of infection, along with high public compliance, helped Taiwan have an outstanding "report card" in the global wave of COVID-19. Choi (2020) also argues that high quality collaborative governance can serve as one solution to the COVID-19 pandemic. 
South Korean experience indicates factors of effective collaboration in response to the pandemic: an effective leadership; identification of the most important partners in the system as well as outside the system; a clear definition of roles and tasks to collaborate partners; a use of multi-lateral democratic processes instead of one-way command and control; facilitation of environment that allows participating actors to develop and implement their own policies; development of suitable channels for efficient feedback; provision of transparent information and swift reactions to requirements to build and enhance mutual trust. Similarly, Christensen and Lægreid (2020) identified a collaborative decision-making style with involvement and participation from stakeholders as crucial determinants of the Norwegian approach.

On contrary, some other studies are arguing that a centralised top-down approach limiting certain citizens' rights was a key success factor in some other Asian countries (e.g., Ang, 2020). From this point of view, it is well worth mentioning that centralised top-down approach, limiting some fundamental rights and freedoms of citizens may not contradict with the principle of collaborative governance automatically, but only by the design of its implementation. This partially corresponds with a crisis management setting under the circumstances of a state of emergency in the observed countries, where the central governments are expected to play the crucial role, and where any deep-rooted tradition of efficient collaborative governance is missing.

\section{Methods}

The authors used qualitative research methods to prepare this text. The main method is the multiple case study, covering two selected countries - Czechia and Slovakia. The authors decide to evaluate countries with a common history and with similar results from the point of COVID-19 spread. Both countries belong to the group of countries that were both unprepared and had no recent relevant past experience (Capano et al., 2020). The choice of similar countries could be the object of discussions; however, it can be well-argued. If similar countries with similar approaches and problems achieve similar results, possible trends/factors may be synthetised. Moreover, there is also a simple pragmatic reason behind our choice - authors cover their own countries, using their deep direct knowledge about a situation.

The text of included country case studies is developed by authors based on their own secondary analysis of existing public data and via the use of the expert opinion method. The data were collected by monitoring official national COVID-19 related sites (CZE: koronavirus.mzcr.cz and SVK: www.korona.sk) and by monitoring a wide range of pro- and anti-government popular newspapers.

In both countries, we selected four experts and asked them to respond to a semi-open questionnaire, listing alternative policy responses and providing a lot of space for their own opinions. They were to evaluate/discuss the proposed measures, responses and problems, and were invited to add their own proposals or important remarks. In the later phase we re-contacted them for 
specific responses to particular open questions. In Czechia the profile of experts was as follows - two practitioners: the former vice-minister of health and the former hospital director/former advisor to the Minister of Health and two academicians - health policy experts. In Slovakia we received responses from one practitioner, the former head of the Parliamentary Committee for Health and from three academicians, one public policy expert, one health policy expert and one public finance expert. The choice of experts was intentional (we wanted to include both practical and theoretical elements) and based on our existing contacts to ensure the response (thanks to this all experts responded).

The paper also utilises the method of qualitative comparative policy analysis (Rihoux et al, 2011). This method develops a conception of causality that leaves room for complexity.

As the main health outcome indicator, the number of COVID-19 newly infected cases is used as the simple and available proxy of results of anti-pandemic policies. Statistics delivered by Czechia and Slovakia about the number of newly infected cases are internationally accepted and can be used for careful comparisons, especially when evaluating the first phase of the pandemic when both countries delivered similar relative size of testing before November 2020 (after blanket testing in Slovakia many units testing with antigen tests remained open for free and for everybody interested, adding thousands of extra cases into the statistics).

To respond to the overall research question of this article, two concrete research questions are formulated, as follows:

RQ1: Is there any possible collaborative governance related explanation for very good (Czechia) or excellent (Slovakia) pandemic control results in spring?

RQ2: Is it possible to propose collaborative governance related explanations determining really problematic health outcomes during the second wave?

To be able to respond to the second research question within the limits of the size of this article we have had to select a few critical collaborative governance challenges for our evaluation. The basis for this were the responses from experts, which identified the following core areas to be included - low capacity to deliver evidence-based policy making (especially due to the inability to engage stakeholders and to listen to them), miscommunication, political fights instead of working together against COVID-19, leadership competences, administrative capacity and competences.

\section{Czech experience with COVID-19}

Czechia is a Central European country with a territory of 78,866 km2 and 10.5 million inhabitants. The Czech healthcare system is based on competitive compulsory public health insurance, which assures universal access to a broad benefit package. According to WHO (Alexa et al., 2015), some impor- 
tant Czech health indicators are above EU averages or even among the best in the world (such as infant mortality). On the other hand, there is a possible substantial potential in Czechia for efficiency gains (to cope with constant financial problems) and improved health outcomes. From the point of inputs, the Czech health care system is one of the most developed in the region, it spends app. 7.5\% from GDP, employs 4.1 physicians and 8 nurses per thousand inhabitants and its bed capacity is 6.6 beds per thousand inhabitants (WHO data).

\subsection{First wave of the pandemic}

In Czechia, the first three COVID-19 cases were recorded on 1st March. The relatively steep increase in new cases peaked at the end of March and then started to gradually decrease. The number of hospitalised COVID-19 patients only exceeded 400 in the first half of April (with a peak of 437 patients on 9th April). The number of patients in a serious condition only exceeded the level of 100 twice.

The Czech government's response was designed in close collaboration with epidemiological experts and applied fairly measures similar to other countries. It focused on social distancing measures, protection of the most vulnerable population groups, diminishing the risk of importing the virus from abroad, and testing. A massive emphasis on an obligation to wear face masks (and compliance with this duty) became a significant feature of the Czech response.

From the evening of 10th March, the Czech Health Ministry banned all cultural and sporting events of more than 100 people. The following day, pupils and students were banned from attending all schools. From 12th March, a 30-day state of emergency was declared, extended various times and ended on 17 th May 2020.

The most critical restrictions on citizens' rights were implemented very fast (see for example Spacek, 2020), such as the reintroduction of border surveillance; restricted entry to the country; mandatory quarantine for returnees from abroad; restrictions on the free movement of people; rules for tracing infected people (only with their permission); bans on movement without covered mouths and noses; and restricted visits to hospitals, prisons and social care establishments. Various restrictions on services (public and private), restriction/suspension of administrative activities; restrictions on transport services; and bans on some cultural, sport and other activities were also applied. Sports facilities, libraries, galleries, shops, markets, services and retail sales (with exceptions) were closed. The most infected areas of the country were temporarily isolated -21 municipalities in the Olomouc region, with approximately 24,000 people, were closed for two weeks from 16th March.

Commencing 17th March, acute inpatient healthcare providers were forced to reduce planned medical services to those "essential" for the health of their patients. Two days later (19th March), the ministry ordered healthcare providers to reserve a certain number of beds (preferably beds equipped with 
artificial pulmonary ventilation or oxygen therapy) for COVID-19 patients. Admission of new patients for follow-up inpatient rehabilitation care was prohibited on 23th March. The ministry's measures effectively helped to prevent the overloading of inpatient care.

Czechia started easing COVID-19-related restrictions from mid-April - according to a publicly announced scheme. The country returned to an almost standard way of life in late May.

\subsection{Second wave of the pandemic}

Compared to the first wave, the health outcomes of the second wave are far more critical (Figure 1). Up to 21st January 2021, there have already been a total of 924,847 registered COVID-19 cases in Czechia (862 cases per one hundred thousand populations - ranked number four worldwide, with only very small countries in front of it).

Figure 1: Indicative curve illustrating the development of the number of newly infected cases in Czechia

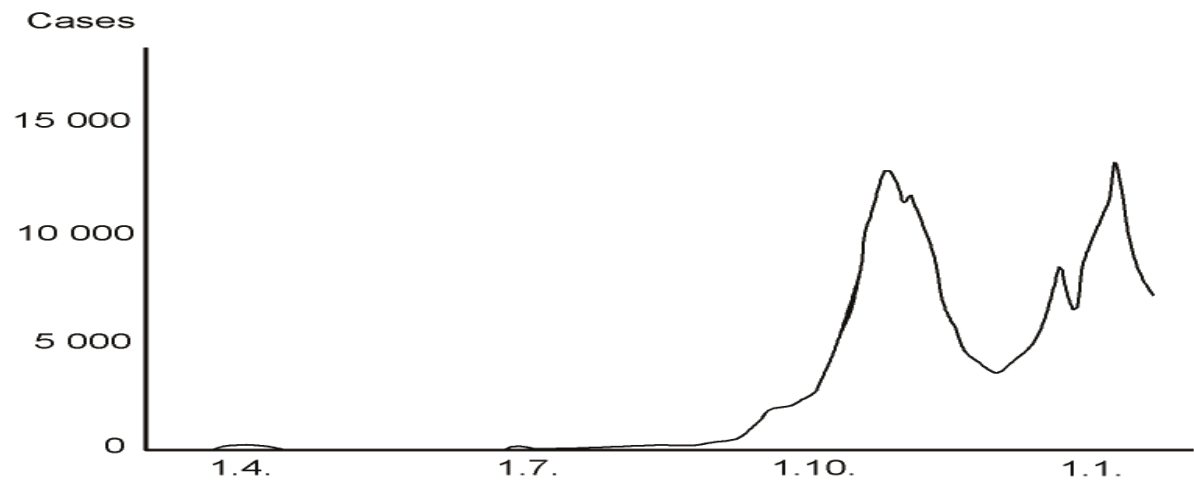

Source: authors

The numbers of newly infected cases started increasing again in July 2020. In August, the government rejected any major restrictive measures, referring to the alleged local character of epidemy. Similarly, citizens did not respond by increasing social distancing, so the infection rate trend started rocketing (for example on August 21 the number of newly infected cases had already reached 504 and several local pandemic focal points were fully visible, especially in Northern Moravia). Both the Czech government and the Prime Minister, Mr. Babiš, continued to deny the return of COVID-19 during this period. For example, he told deputies "Don't deal with COVID-19 all the time, try to solve the gardening law for example".

September was characterised by a fast increase in the number of newly infected cases and the COVID-19 tracking system began to collapse. Only when the numbers of infected achieved record numbers in September did the Prime Minister publicly announce the return to strict anti-pandemic measures 
and apologised for the delayed reaction. Despite being a more critical situation, the set of applied anti-pandemic measures was much softer compared to spring and the compliance was not effectively reintroduced.

As late as 5th October the emergency situation regime was reintroduced, schools were closed on 14th October and a "soft" lock-down, including closing most shops, was introduced on 28th October (going to work or to the countryside and many other activities were permitted).

The compliance has suffered from confused and incomprehensible communication as well as lack of good examples provided by government officials. The opposition to adopted measures is also visible. Several groups of mainly small entrepreneurs, who are frustrated because of the lack of effective compensation organised protest actions. Hundreds of protesters demonstrated in Prague for an initiative "Let's open Czechia", in January 2021. Recently, a protest against wearing face masks became the impulse for the first scuffle in the House of Deputies in modern history.

COVID-19 has also spread rapidly among healthcare professionals. At the end of October, the number of COVID-19 positive physicians exceeded 2,500, and more than 6,000 nurses were infected. In reaction to the lack of specialised staff in the health care sector, the government introduced mandatory work duty on 12th October for selected categories of full-time students to compensate for the staff shortages in public health offices, hospitals, emergency care, and residential social services.

\section{Slovak experience with COVID-19}

Slovakia is a small country in Central Europe with a territory of $49,035 \mathrm{~km}^{2}$ and 5.458 million inhabitants. Similar to Czechia, its healthcare system is based on competitive compulsory public health insurance, which assures universal access to a broad benefit package. According to WHO (Smatana et al, 2016) the Slovak health system performs relatively well, but some Slovak health indicators, such as life expectancy, healthy length of life and avoidable deaths, are troubling. There is persistent room for improvement in the delivery of care, of the ineqvity in the distribution of health providers and of the efficiency of resource allocation and use. From the point of inputs, the Slovak health care system lags behind Czechia, but is still one of the most developed in the region, it spends app. 6.7\% from GDP, employs 3.4 physicians and 6.1 nurses per thousand inhabitants and its bed capacity is 5.7 beds per thousand inhabitants (WHO data).

\subsection{First wave of the pandemic}

The first COVID-19 case in Slovakia was detected on 6th March and the peak of infection was reached in late March. Compared to other countries, the COVID-19 outbreak was very limited in spring. Most media stated at the time that Slovakia is the most successful country in Europe in fighting the COV- 
ID-19 pandemic - with a very small number of infected, hospitalised and only 28 COVID-19 related deaths in Slovakia by the end of May.

When the COVID-19 risks became evident, the Slovak government delivered swift and strict responses. On 14th February 2020, a system was already organised on the Slovak borders to identify people who were ill. On 27th February, the first concrete anti-pandemic measures were announced - health status border controls at all Slovak airports and at selected border crossings, especially at the border with Austria.

On 6th March, (the same day that the first COVID-19 case was detected in Slovakia) the government announced restrictions on visits to hospitals, social care establishments and prisons, recommendations that everybody arriving in Slovakia should stay in voluntary quarantine, that cities and non-profit organisations should not organise any mass activities, and that churches should not organise religious activities.

The regional self-governments voluntarily decided to close secondary schools and universities, stopped all contact activities and switched to on-line education before the formal state decision to close all schools and preschool facilities announced on 12 th March.

A restricted emergency situation was formally announced on 11th March 2020; this was very early compared to most other European countries. The scale of the emergency was restricted to the healthcare sector and social care establishments for the elderly, for the rest of the country "an extraordinary regime" status was announced.

After 12th March, anyone arriving in Slovakia from abroad was required to stay in home quarantine for 14 days, almost all retail shops and services were closed. Sport facilities were also closed, the organisation of sports, social, and cultural events was prohibited, all public worship was prohibited; all border crossings were closed and international public transport was restricted.

From 25 March, all citizens were required to wear protective face masks in all public spaces and advised to stay at home as much as possible and to limit any kind of mobility. The most sensitive measure was the decision concerning compulsory state-organised quarantine for everybody returning from abroad after 6th April 2020. A law making it possible to track the location of all mobile phones was passed. A curfew was put in place during the Easter holidays, with limited exemptions such as shopping, travelling to work, health purposes, and individual recreation in the surrounding forests and countryside.

Because the spread of COVID-19 was confirmed in some Roma settlements, the Crisis Staff isolated five Roma settlements in three municipalities (Krompachy, Bystrany and Zehra) on 8th April 2020. Some authors claim that the use of the army to manage this lock-down was problematic, but the core fact is that Roma welcomed and not rejected such help. 
It is necessary to admit that Slovak citizens behaved very responsibly. Except for a few specific cases, the public reaction to the very strict measures was positive. The slogan 'Stay at Home' was promoted and accepted; face masks used regularly.

The pandemic also impacted on the heath care sector - planned operations and other non-urgent treatment in the health care sector were postponed. Selected hospitals were expected to construct drive-through points to test people in their cars for COVID-19. Specialised hospitals to treat COVID-19 were established in all regions.

\subsection{Second wave of the pandemic}

The positive picture related to the first wave of the pandemic is today "replaced" by critical figures during the second wave of the pandemic in the country (Figure 2). Up to 25th January 2021, there have already been a total of 406,258 registered COVID-19 cases in Slovakia (739 cases per one hundred thousand population).

Figure 2: Indicative curve illustrating the development of the number of newly infected cases in Slovakia

\section{Cases}

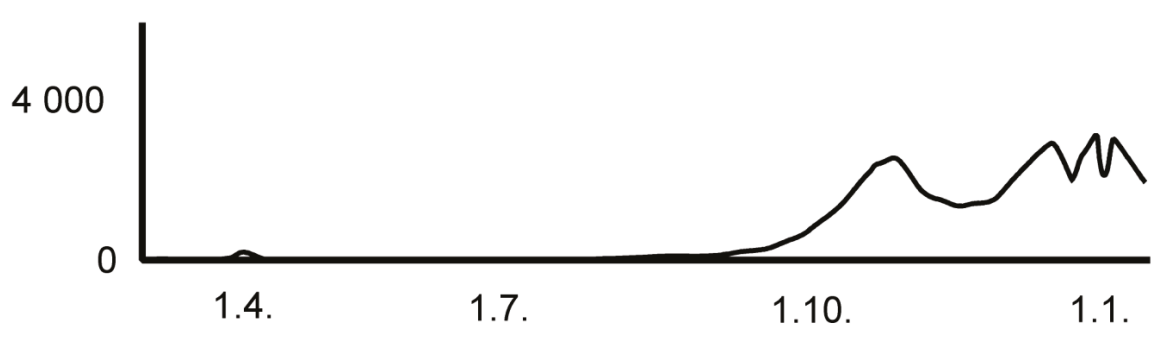

Source: authors

After the relaxation of the existing measures in late spring (May, June) the pandemic situation in Slovakia started to worsen in late July, when the number of infected started to once again increase. The number of newly infected cases reached critical levels in autumn, with the first peak on 29th October - more than 3,600 cases in one day (detected by PCR and antigen tests). The three weekend rounds of blanket testing at the end of October and in early November detected app. 60,000 infected persons and moved the "infection curve" a bit down, but only for a very short period. After the Christmas holidays the number of newly infected cases again rocketed - on 30th December the number of newly infected cases reached 6,315.

Similar to Czechia, such a massive spread of COVID-19 infections cannot be independent from the fact that the growing numbers of infected during late July and early August were not reflected in time by the Government - despite the existing rules of the national pandemic plan approved in spring. Even in 
early September, the Prime Minister rejected proposals from epidemiologists for immediate re-introduction of strict anti-pandemic measures. However, he changed the rhetoric on 25th September - telling people that strict measures are necessary, because "people ... you let me down".

Anti-pandemic measures similar to those in spring were re-introduced but in a much softer way compared to spring. The most visible anti-pandemic measure was closing schools - but as late as on 26th October. The strategy of the Prime Minister was not to use lock-down to reflect increased rates of newly infected, but decided in late October on a unique experiment - blanket testing by antigen tests of almost the entire population. Testing during the first stage was realised in three phases (up to now, more phases are possible) the four most infected districts on 23-25 October, the whole country on 31st October to 1st November, and 45 districts on 6-7 November which had had a higher incidence rate from the second phase. In the largest scale second phase 3,625,332 people were tested, with 38,359 positive results. This mass testing was envisaged by the Prime Minister as the "nuclear weapon" against COVID-19, however most experts do not agree with such optimism - see our later analysis.

Just before Christmas the government introduced some so-called "lockdown" measures, but these were really soft (shops were not closed, family contacts only formally limited, etc.). At the end of December, when the numbers of infected (and deaths) after social contacting during Christmas had rocketed and the capacities of hospitals started to be fully utilised, the Minister of Health, pushed by medical experts, originated the passing of much stricter lock-down rules from 1st January.

During the second week of January the Prime Minister again announced that blanket testing is necessary to cope with the pandemic - after this announcement a comprehensive discussion started also within the coalition, which lasted for one week. In the end, on 17th January, the plan of country wide semi-compulsory (those without a negative test were prevented to leave their homes, except for urgent needs, similar to autumn) "screening" was approved by the Government, with commencement on 18th January (!).

\section{Discussion: How to explain the results for the first wave of pandemic?}

Czechia and Slovakia were very successful in controlling the COVID-19 spread in spring (Figure 3). Some Western media (like The Guardian on 5th May 2020) came to the assumption that the very limited spread of COVID-19 in postcommunist countries was related to the limited performance of national health care systems and related low trust in the chance of receiving effective treatment. The authors do not agree with this idea - for example, according to the recent study realised by the Slovak Academy of Sciences of Slovak, $75 \%$ of the population trusted in their health care system in April 2020 (SAV, 2020). The situation in Czechia is similar. According to CVVM survey (2020), 
more than two-fifths (44\%) of the population were satisfied with the health care system, slightly more than a fifth (22\%) were dissatisfied and one third (33\%) were "neither satisfied nor dissatisfied" in 2019.

Figure 3: Relative COVID-19 outbreak on 26. 5. 2020 (selected countries number of newly infected cases per 100,000 inhabitants)

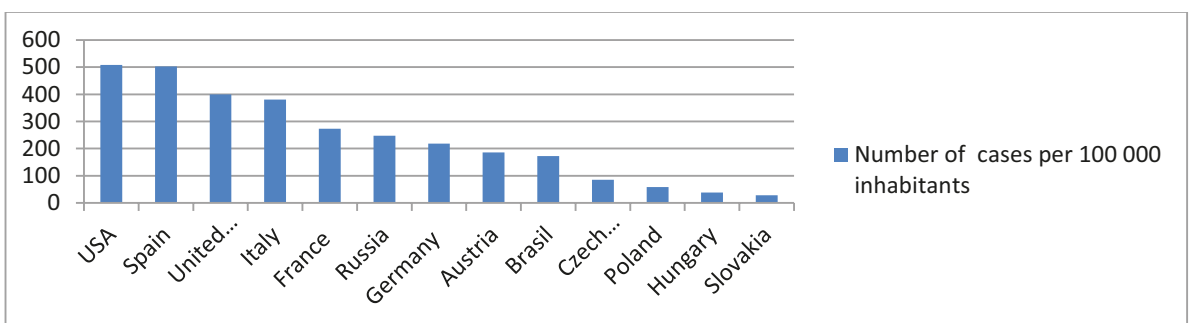

Source: authors, based on the data published by Johns Hopkins Coronavirus Resource Center

It seems that the high level of compliance could be related to other factors, though not as yet comprehensively mapped. The authors feel that factors like common solidarity, fear, path-dependence and political background should be taken into account. During the first phase, both the Czech and Slovak nations (with minimum exceptions) managed "to work together" - the Slovak national password for that period was "We can do it together". An exclusive public opinion poll in Slovakia in March showed that almost $80 \%$ of all respondents supported the central government's anti-pandemic measures, and surprisingly, approximately $13 \%$ of the respondents would have welcomed even an even more restrictive state response to the pandemic.

The path-dependence factor could be connected with 40 years' experience of living in a centralised non-democratic regime where citizens were expected to "serve the state" and not the opposite "the state is here to serve citizens and businesses". Even after 30 years following the change of regime, governments "ordered" and people followed.

Lastly, two elements are connected especially with Slovakia. The first is fear (although this factor is relevant for Czechia, too). Not only was everybody afraid of what kind of disaster was coming, but in Slovakia, the Institute for Health Policy (policy unit at the Ministry of Health) published its prognoses of the spread of this pandemic in Slovakia. According to the first of them, the total number of infected with "laisse-faire" approach was expected to reach almost $50 \%$ of the population - such a critical message probably influenced the behaviour of citizens. One of the interviewed Slovak experts emphasised this factor specifically:

"At the beginning, the important factor was fear, caused by international developments and preliminary prognoses published by the Ministry of Health. The government communication in the media and by official pages 'promoted such fear'". 
The second is smooth political transformation and the existence of political co-operation related to the fight against the COVID-19 spread. The departing Prime Minister, Mr Pellegrini, did not decide to wait until the end of office in a passive or moderate way, but managed during the last days of office of "his" government to realise a set of really comprehensive measures to prevent the spread of COVID-19 in Slovakia. The newly elected Prime Minister was invited to be part of the team and this allowed for continuity. Politics was very much set aside; the coalition and opposition parties prioritised the need to fight COVID-19 instead of the need for permanent political fights.

Without doubt, not everything was perfect regarding the public polices related to COVID-19 during the first phase of this pandemic. Public policy actors criticised the government because of fragmented, often confused, and inconsistent communication, lack of systematic approach to COVID-19 response, and rather delayed implementation of standard legal procedures foreseen by the law to deal with crises. It seems the governments also slightly underestimated the impact of the pandemic from the outset. As a result, the countries (especially Czechia) struggled heavily with a lack of protective equipment in the first weeks. Similarly, testing was not organised smoothly, the government failed to prepare adequate testing capacities. In Czechia, one month after the first case occurred, waiting times for test results often exceeded a week. In both countries the economic response was slow and limited - especially in Slovakia (for more see Nemec and Spacek, 2020).

\section{Discussion: Possible collaborative governance related explanations of problematic health outcomes during second wave}

As indicated in the methodology part, the authors - based on expert opinions - decided to deal with the following factors in this part of the text: low capacity to deliver evidence-based policy making (especially due to the inability to engage stakeholders and to listen to them), miscommunication, political fights instead of working together against COVID-19, leadership competences, administrative capacity.

\subsection{Evidence-based policy making and involving stakeholders}

During the second phase it became fully evident that the top leaders were not able or maybe even unwilling to engage all the relevant stakeholders (especially experts) and to listen to them. Expert opinions and advice were rejected mostly because of populistic reasons. In Czechia, a reputable epidemiologist, Mr. Mad'ar, had already stepped back from the expert advisory body in August 2020 because of the Ministry of Health's chaotic conduct and communication failures. In Slovakia, several experts (e.g., Мr. Krčméry) left "the team" of the Prime Minister and switched to the expert team established by the President.

Protective measures or even strategies were often declared without any consultations with stakeholders. For example, the Czech Medical Chamber several 
times expressed the concern that the Ministry did not consult its vaccination strategy with experts. In Slovakia, the Medical Chamber openly protested against the selected measures (especially against blanket testing) - in retaliation, the Prime Minister publicly named the Chamber as "misbelievers" (28th October).

Critical stakeholders in both countries, especially local and regional self-governments, civil society, and professional organisations, were not only insufficiently consulted, but also not accepted as real partners and a top-down approach in decision-making dominated. For example, the warning tool called "COVID-19 Traffic Lights" was developed by the Slovak capital, Bratislava, and then it was taken by the Ministry of Health, but only as a one-way process. Without any consultation, the central government pressed sub-national governments to implement chaotic and non-strategic measures regardless of their protests or warnings. Furthermore, if we put these events together with the increase of additional expenditures as well as shortfalls in their own revenues (e.9., Čajková et al., 2021; Černěnko et al., 2021), it helps us to understand the frustration and helplessness of their representatives. Unsurprisingly, distrust in sub-national governments towards the central governments was continually increasing in 2020.

The Slovak case of blanket testing may serve as a really good mirror of the situation. Both waves of testing were initiated directly by the Prime Minister, who continually argued that such testing serves as a "nuclear weapon" against COVID-19 spread. The participation of citizens in testing was secured by the rule that without a negative test, people must stay at home and cannot go to their work or to the countryside.

Already in relation to the first three weeks of testing in autumn, most experts were strongly against it, arguing especially of the high social and economic costs, limited capacities of medical personnel necessary to deliver testing, risk of spreading the virus when waiting for treatment and its results and also by the very limited reliability of results of antigen testing in cold weather. To "win", apart from unfairly blaming his opponents, the Prime Minister also publicly announced: "either testing, or my resignation".

The experience from the first round of blanket testing definitely proves that the expectations of the Prime Minister about "his nuclear weapon" did not materialise. Yes, the direct benefit of blanket testing is indisputable - during its three phases, the testing identified almost 60,000 infected, who were required to stay in quarantine and by this the spread of the virus was most certainly slowed down.

However, several cons should also be mentioned. Formally, the testing was voluntary, however, because of the related sanctions frustration, fear, and strong opposition was created. The logistics required many health-care workers, assistants and the army - yet 12 hours before the start of the main wave, only $60 \%$ of posts had been filled by all the staff required. Another issue was the hundreds of people queuing outside for hours, especially in the larger cit- 
ies on the first day of the weekend of country-wide testing (30 October -1 November). The direct costs of testing are estimated at more than 100 mil. EUR.

Most critical is the fact that the blanket testing used is a "single" anti-pandemic tool. Because the reliability of antigen tests is rather limited (existing experiments indicate these tests have a $50-70 \%$ success rate to identify positive cases in the population without symptoms), up to 50,000 infected received a "green card" - the option to behave as healthy people and not to comply with social distancing measures after mass testing. In such conditions the fact that the blanket testing impact on the incidence curve was only short-lived cannot be any surprise.

\subsection{Mis-communication}

The quality of communication from government to citizen and all relevant stakeholders suffered from many deficiencies. The experts involved in this study commented on this especially with two critical statements:

"Too much was not effective"

"Their information was frequently chaotic"

In spring, press conferences were organised even several times a day, announcing new measures, their modifications, interferences, etc. During the second phase the frequency of communication outputs decreased, but the quality of communication did not improve significantly (despite already existing experience) with the pandemic. Some opposition media in Czechia like to call the Minister Havlicek "Prime Chatterbox".

The "quality" of communication of the Slovak Prime Minister in late autumn and winter crossed any acceptable borders. In many cases, with his highly problematic statements, he dishonoured experts, politicians or other actors with different opinions to his. His statements on 13th January during an official press conference related to the second phase of blanket testing serve as an effective example of the style of his communication:

"If any expert now says that we need vaccination and not blanket testing, such a person is a fool and not an expert."

"If our medical experts are such good experts, why have they not already produced a Slovak vaccine?"

In autumn, the Prime Minister explicitly blamed almost everybody (e.g., political opposition, media, experts, ordinary people, doctors in hospitals as well as GPs, and even some members of the ruling coalition) but not himself. It is no surprise that trust in him and his government significantly dropped if one compares its level at the time of the general election in 2020 with the end of the same year. 


\subsection{COVID-19 as the subject (and "victim") of political fights}

Compared to the first phase of the pandemic, when most political actors tried to work together and compliance and solidarity were high, the situation significantly changed from the summer.

Compared to the specific political situation in spring (especially in Slovakia - see above) in both countries during the second phase of the pandemic, (almost) any COVID-19 policy proposal is used as the option for political battles - opposite to the need to find commonly accepted and effective solutions to limit the spread of the virus. (Almost) any proposal from the government coalition is automatically subject to criticism by the opposition, even in cases where such legislation is necessary.

It is not only the opposition "automatically" fighting any proposal by the government coalition. In Slovakia, the situation within the coalition is also especially critical. The most visible fight is between the Prime Minister (party OLANO) and the Minister of Economy, Mr. Sulík (party SaS). The "apex" of this fight was the press conference of the Prime Minister on 11th January when Mr. Matovič directly accused Mr. Sulík of causing 4,300 preventable deaths because he had ignored the order to purchase antigen tests. The fact that the coalition needed one week of internal fights to propose the final design of the second round of blanket testing is also fully illustrative and its results critical (the second round of blanket testing was announced to start on 18th January, but the government decree only came into force on 19th January, leaving no time to prepare for its implementation).

Politics without doubt also impacted the capacities of governments to implement necessary anti-pandemic measures during the second wave of pandemic. The solidarity and "subordination to top-down orders" characterising the spring wave disappeared and many measures were not only criticised by the opposition, but also disliked by citizens and businesses. In both countries, several mass protests against COVID-19 related policies have been organised, with the peak related to 17 th November (Velvet Revolution Day).

\subsection{Leaderships}

The Prime Minister's leadership competences in both countries are a matter of widespread concern and discussion. The Slovak situation is already sufficiently documented above ("just me" performance).

Regarding Czechia, the Prime Minister (probably trying to follow advice from his marketing team) seems to pay too much attention to operative tasks ("I am counting vaccines", "I'll deliver face masks by myself" and similar expressions document this). More appalling, Mr. Babiš many times failed to bear responsibility for mistakes or wrong decisions.

As the result of missing leadership, the governments have chronically failed to prepare and implement strategic or complex and coordinated policies. In both countries, formal rules of how to react to the level of pandemic spread 
were not prepared in time in spring, but most importantly, existing strategies have not been respected by practice in summer which has most certainly been one of the factors determining the excessive number of newly infected cases in autumn. In addition, vaccination strategies arrived late and have been changed several times in both countries.

Because of the lack of real strategic leadership, the crisis management is characterised by prioritising operational management over strategic, resulting in confusion, oppositeness, and ultimately the immaturity of government actions.

A specific problem of both countries is the negative examples of misbehaviour by core leaders. In Czechia, the Minister of Health Prymula was caught by the media in a pub (formally closed) without a protective mask (the positive is that he was dismissed after this). The Slovak Vice-Prime Minister Holly was caught by the media travelling regularly to and from the UK for family reasons - without testing and quarantine (he was not dismissed and part of the government became ill after one of his returns). The Slovak Head of Parliament was involved in a car accident during lock-down; a former Miss Slovakia was in his official car (he did not resign).

\subsection{Administrative capacity}

According to the international rankings (see for example Thijs et al., 2017) the administrative capacities of both Czechia and Slovakia are among the lowest in the EU. It was possible to "ultra-mobilise" them in spring, but in a long-term perspective their weaknesses had to become visible. A few examples can be provided.

Lagging digitalisation of administration in both countries has limited the chance to effectively fight COVID-19. Effective tracking of infected, tracking of movement of suspected, protection of borders, help for impacted businesses and many other needed processes did not work, this is also due to limited IT support. During the first round of blanket testing in Slovakia all evidence (registration, results) was by hand, without any IT support. Such failings significantly extended waiting times and increased the risk of infection spread between people waiting. What really cannot be excused is the fact that this problem was repeated (to a large extent) also during the second round of blanket testing in January - only a limited number of testing points allowed to pre-order and to receive results on-line.

Limited administrative capacity can be documented by the low-quality design of issued regulations which needed several amendments. This resulted in explanations needed for their implementation and further explanations of the comprehensive sets of unclear exceptions to the regulations. The enforcement of such legislation was very difficult with significant negative impact on its execution and compliance. 
Limited administrative capacities (not lack of available resources) could also be behind the fact that the economic support to business and people in need was limited in both countries (and with many mistakes and problems). The Czech government had managed to pump app. 12\% of the GDP (Germany $16 \%$ in 2020 and the Slovak government only app. $6 \%$ of GDP. Low quality of e-government and complicated rules of supporting schemes created opportunity for fraud and false claims for support (like the case of a hotel in the city of Prievidza receiving more than 100,000 EUR of ineligible compensation).

\section{Conclusion}

This article attempts to summarise what the Czech and Slovak governments have done in response to the COVID-19 pandemic and why these governments achieved different results for the first and second phase of the pandemic. Based on comprehensive case studies and following analysis, we suggest that in countries with limited quality of collaborative governance and without experience with similar pandemic, some short-term "ultra-mobilisation" and positive results are possible, but that failures are non-avoidable from the long-term perspective. During the second wave of the pandemic, serving as a catalyst, governance weaknesses, together with other factors, led to massive governance failures. As a result, the governments' responses delivered very limited results in terms of the prevalence of COVID-19.

Complex and inclusive collaborative governance is especially based on mutual respect, understanding, trust and shared capacities. In addition, a large-scale crisis requires a dynamically scaling collaboration that can adapt to changing problems (Ansell and Torfing, 2015). Our analytical look at events that happened during the first and the second wave shows that such a base was not present during the second wave of the pandemic. The turning point when the shortcomings of collaborative governance started to impact the spread of pandemic in a significant way in both countries was the end of the first wave and a "seamless summer of 2020".

As for Slovakia, various stakeholders became much more active when they found the central government had not prepared for the second wave in a proper way - and their activities made the problems very visible. Mutual respect, as well as understanding, immediately disappeared not only between the central government and other stakeholders, but also between the partners within the ruling coalition. The government, and especially the Slovak Prime Minister did not want to listen any advisors, including experts in epidemiology or economists who had repeatedly wanted to warn him to take scientifically unsubstantiated measures. Furthermore, it was impossible to see clear lines of some visions: the state of health of the population as well as the state of some sectors of the national economy became dramatically worse. Instead of building on existing elements of collaborative governance the central governments stuck on one-way command and control; feedback was understood as an attack on the government's leading role; transparency of policy making became rare. In Czechia, COVID-19 emphasises some public admin- 
istration long-lasting blind spots regarding its competences and capacities. The system was not effective in dealing with complex policies that required coordinated and strategically well-designed solutions even before the pandemic. Combined with the government's bad communication and leadership failures, it has serious consequences for public confidence, compliance level, and subsequently for the spread of the disease. Governance style oriented solely on short-sighted political marketing works well in good times. In bad times, sooner or later, it inevitably fails. From the theoretical point of view, these events showed an imbalance in the use of power (e.g., Purdy, 2012). Thanks to available resources and rules of crisis management, central governments, and the Prime Ministers in particular, dominated. However, instead of facilitation of collaborative initiatives and joint actions of various stakeholders that could lead to synergy, inclusiveness, mutual trust and understanding, they preferred politics and their own narrow interests. The price for the mentioned events is many probably preventable deaths, not only because of the COVID-19 infection itself, but also because of the pandemic consequences, especially in the form of limited access to necessary treatments.

The analysed events in both countries offer us three very important policy implications. First of all, in emergency situations when the governments are challenged by turbulent problems and volatile demands, emotional and politically-driven decisions cannot prevail over strict evidence-based policy making. Secondly, collaborative governance seems like a key strategy in coping with the mentioned turbulent problems which go beyond the capacities of individual governments because "done well, collaboration creates synergies between governments and private participants, allowing them together to produce more than the sum that their separate efforts would yield" (Donahue and Zeckhauser 2011: 5). However, each shortcoming or underrated context can deteriorate the positive effects of collaboration and, at the end of the day, it is nothing more than a Potemkin village. And last but not least, although the pandemic crisis activated all the drivers for the application of collaborative governance pointed out by Emerson et al. (2012), i.e., leadership, consequential incentives, interdependence, and uncertainty, the Czech and Slovak examples show that leadership is a key, and at the same time, the most sensitive driver, and without adequate leadership, other drivers cannot automatically generate effective collaboration.

\section{Acknowledgement}

Preparation of this paper received support from a project of the Czech Science Foundation (GA19-06020S). 


\section{References}

Alexa, J. et al. (2015). Czech Republic: Health system review. Health Systems in Transition, 17(1), pp. 1-165.

Ang, Y. Y. (2020). When COVID-19 Meets Centralized, Personalized Power. Nature Human Behavior, 4, pp. 445-447. https://doi.org/10.1038/s41562020-0872-3.

Ansell, Ch. and Gash, A. (2008). Collaborative Governance in Theory and Practice. Journal of Public Administration Research and Theory, 18(4), pp. 543-571. https://doi.org/10.1093/jopart/mum032.

Ansell, Ch., Sørensen, E. and Torfing, J. (2020). The COVID-19 pandemic as a game changer for public administration and leadership? The need for robust governance responses to turbulent problems. Public Management Review. At < https://doi.org/10.1080/14719037.2020.1820272>, accessed 25 January 2021.

Ansell, Ch. and Torfing, J. (2015). How does collaborative governance scale? Policy \& Politics, 43(3), pp. 315-329. https://doi.org/10.1332/03055731 $5 \times 14353344872935$.

Bouckaert, G. et al. (2020). European Coronationalism? A Hot Spot Governing a Pandemic Crisis. Public Administration Review, 80(5), pp. 765-773. https:// doi.org/10.1111/puar.13242.

Bryson, J. M., Crosby, B. C. and Stone, M. M. (2006). The Design and Implementation of Cross-Sector Collaborations: Propositions from the Literature. Public Administration Review, 66(1), pp. 44-55. https://doi. org/10.1111/j.1540-6210.2006.00665.x.

Capano, G. et al. (2020). Mobilizing Policy (In)Capacity to Fight COVID-19: Understanding Variations in State Responses. Policy and Society, 39(2), pp. 285-308. https://doi.org/doi: 10.1080/14494035.2020.1787628.

CVVM. (2020). Česká veřejnost o zdravotnictví - prosinec 2019. Prague: CVVM.

Choi, Y. J. (2020). The Power of Collaborative Governance: The Case of South Korea Responding to COVID-19 Pandemic. World Medical and Health Policy, 12 (4), pp. 430-442. https://doi.org/10.1002/wmh3.376.

Christensen, T. and Lægreid, P. (2020). Balancing governance capacity and legitimacy - how the Norwegian government handled the COVID-19 crisis as a high performer. Public Administration Review, 80(5), pp. 774-779. https:// doi.org/10.1111/puar.13241.

Čajková, A., Butoracová Šindleryová, I. and Garaj, M. (2021). The COVID-19 Pandemic and Budget Shortfalls in the Local Governments in Slovakia. Scientific Papers of the University of Pardubice, 29(1), 1243, pp. 1-14. https:// doi.org/10.46585/sp29011243.

Černěnko, T., Neubauerová, E. and Zubal'ová, A. (2021). Impact of the COVID-19 Pandemic on the Budget of Slovak Local Governments: Much Cry and Little Wool? Scientific Papers of the University of Pardubice, 29(1), 1249, pp. 1-13.

Donahue, J. D. and Zeckhauser, R. J. (2011). Collaborative Governance. Private Roles for Public Goals in Turbulent Times. Princeton/Oxford: Princeton University Press.

Emerson, K., Nabatchi, T. and Balogh, S. (2012). An Integrative Framework for Collaborative Governance. Journal of Public Administration Research and Theory, 22(1), pp. 1-29. https://doi.org/10.1093/jopart/mur011. 
Howlett, M., Capano, G. and Ramesh, M. (2018). Designing for Robustness: Surprise, Agility and Improvisation in Policy Design. Policy and Society, 37(4), pp. 405-421. https://doi.org/10.1080/14494035.2018.1504488.

Huang, I. Y. (2020). Fighting COVID-19 through Government Initiatives and Collaborative Governance: The Taiwan Experience. Public Administration Review, 80(4), pp. 665-670. https://doi.org/10.1111/puar.13239.

Joyce, P., Maron, F. and Reddy, P. S. (eds.). (2020). Good Public Governance in a Global Pandemic. Brussels: IIAS-IISA.

Liu, Y. and Saltman, R.B. (2020) Policy Lessons from Early Reactions to the COVID-19 Virus in China. American Journal of Public Health, 110(8), pp. 1145-1148. https://doi.org/10.2105/AJPH.2020.305732.

Nemec, J. and Spacek, D. (2020). The COVID-19 pandemic and local government finance: Czechia and Slovakia. Journal of Public Budgeting, Accounting \& Financial Management, 32(5), pp. 837-846. https://doi.org/10.1108/ JPBAFM-07-2020-0109.

Parker, C. F. et al. (2020). Collaborative Crisis Management: A Plausibility Probe of Core Assumptions. Policy and Society, 39(4), pp. 510-529. https://doi.org/1 $0.1080 / 14494035.2020 .1767337$.

Purdy, J. M. (2012). A Framework for Assessing Power in Collaborative Governance Processes. Public Administration Review, 72(3), pp. 409-417. https://doi.org/10.1111/j.1540-6210.2011.02525.x

Ramus, T., Vaccaro, A. and Brusoni, S. (2017). Institutional Complexity in Turbulent Times: Formalization, Collaboration, and the Emergence of Blended Logics. Academy of Management Journal, 60(4), pp. 1253-1284.

Rihoux, B., Rezsohazy, I. and Bol, D. (2011) Qualitative Comparative Analysis (QCA) in Public Policy Analysis: An Extensive Review. German Policy Studies, 7(3), pp. 52-58.

SAV (2020). Ako sa máte, Slovensko? Bratislava: SAV.

Smatana, M. et al. (2016). Slovakia: Health system review. Health Systems in Transition, 18(6), pp. 1-210.

Spacek, D. (2020). COVID-19 - National Government Approach in the Czech Republic. In: P. Joyce, F. Maron and P.S. Reddy, eds., Good Public Governance in a Global Pandemic, Brussels: IIAS-IISA, pp. 259-268.

Thijs, N., Hammerschmid, G. and Palaric, E. (2017). Characteristics of EU Public Administrations: Synthesis report. Brussels: EU Commission. 